\section{Combating counterfeit drugs}

Twenty West African countries are launching a joint programme to combat the global trade in counterfeit medicines, believed now to be big business as well as a serious cause of needless death.

The campaign is backed by the United Nations' World Health Organization (WHO) in Geneva and its collaborating networks of research and training institutions worldwide. Pill piracy involves copies of medicines such as insulin, antibiotics and antivirals.

In one recent case, more than 100 Nigerian children aged under six years died after being given paracetamol, a pain killer, containing an industrial solvent.

Nigerian children suffering from malaria have also died after being treated with fake antimalaria drugs. Health authorities in Mexico have seized thousands of counterfeit burn remedies containing sawdust. In India, 14 hospital patients died recently after being treated with industrial rather than hospital grade glycerine. Hospitals and pharmacies in Europe have also been extensively abused by the forgers.

The health services of the poor countries, lacking training and testing facilities, are particularly vulnerable.

The West African initiative follows an agreement reached last year by representatives of 20 national health authorities at a regional meeting in Lomé, the capital of Togo, to combine resources against piracy. The meeting, brought together by WHO and the International Federation of Pharmaceutical Manufacturers Association, called for investment in education and quality control facilities. The programme will pay particular attention to the chronic shortages of medicines for tractable diseases, where forgers are likely to do most damage.

The programme builds on a pioneering experiment in Nigeria, financed by a $\$ 68$ million loan from the World Bank (equal to the country's annual health budget) when health workers were trained to identify fake or substandard medicines and laboratories established to carry out regular spot checks.

David Radel, a senior population and health specialist with the World Bank's Africa regional programmes, says that basic drugs such as antibiotics, antimalarials and agents to eliminate parasites are almost nonexistent, and that many of the drugs that can be had "are either fake, diluted or adulterated".

In the past decade, the illicit trade has become global, provoking judicial investigations in Europe and North America.

Much of the trade originates from developing countries that do not recognize the patents owned by the multinational drug companies. But Thailand, whose substandard medical products have recently gained a global market, is about to change its policies on intellectual property, and other countries may well follow suit.

According to unofficial estimates by government health officials and drug company representatives, fradulent products are creating substantial problems in many countries, including Bangladesh, Colombia, India, Indonesia, Brazil and Pakistan as well as Nigeria and its neighbours.

"All it takes is a person with access to a small laboratory, a total disregard for human beings and a touch of larceny in the heart," according to Milton Silverman, Mia Lydecker and Philip Lee of the Institute of Health Policy Studies, School of Medicine, University of California in San Francisco.

Some people estimate that fake drugs comprise at least a fifth of the products sold in Brazil's nonhospital pharmacies. Many state pharmacy inspectors are understood to supplement their $\$ 115$ monthly salary by helping druggists to ignore professional requirements.

In Indonesia, up to a third of the most widely used drugs may be fakes. Although the counterfeiters are easily caught, the usual punishment of three or four months imprisonment is hardly a deterrent, given the profits that can be earned.

The legitimate pharmaceutical companies, with sales of $\$ 150,000$ million a year, have hitherto been reluctant to acknowledge the problem for fear of losing consumer faith in their products. But some of them are beginning to cooperate with WHO to suppress the trade. The Swiss company Ciba-Geigy has provided specialist training, equipment and managerial advice in the establishment of a pharmaceutical quality control laboratory just opened in Yaoundé, the capital of Cameroon.

Nigeria's federal government has so far spent $\$ 2$ million on training and technology and set up specialist medical task forces for each of its 21 states. International assistance and the West African regional endeavour may well widen the programme and establish a development pattern helping other poor countries to control pill piracy.

Nigeria is using the World Bank loan to improve the supply of quality medicines in the states of Bendel, Cross River, Gongola and Kwara. The money will be invested in specialist training and laboratory facilities to revitalize the inadequate drug supply system and improve the way medicines are imported, manufactured, stored and distributed.

Thomas Land

\section{Indian centre receives funds}

New Delhi

A BOMBAY-BASED pharmaceutical company will fund biotechnology research at the International Centre for Genetic Engineering and Biotechnology (ICGEB) in New Delhi in what may prove to be an important contractual arrangement between an Indian private company and an international research centre.

Under an agreement reached with the United Nations Industrial Development Organization (UNIDO), Wockhardt Limited of Bombay will pay Rs $\mathbf{5 0}$ million (£1.2 million) to the biotechnology centre for development of five products which Wockhardt will have the right to market in India.

ICGEB director Dr K.K. Tiwari said that the Indian government has approved the agreement and the company has paid the first instalment of Rs 5 million to UNIDO. The rest will be paid over a period of five years.

Under the agreement, ICGEB will develop hepatitis-B vaccine, insulin, erythropoetin and two other biotechnologybased products. The Indian company will carry out toxicological studies and clinical trials before marketing the products commercially. Tiwari said work on those products has already begun and "we expect to start clinical trial on at least one product within a year".

ICGEB with two laboratories - one in New Delhi and the other at Trieste in Italy - was created by UNIDO to provide a training base for scientists in developing countries and to develop relevant products. Forty-four counties are members of ICGEB, but none except the host countries - Italy and India - have made any contributions for running the centre. Contracting research to a private company is viewed by UNIDO as a step to augmenting the resources and keeping ICGEB going until member countries start paying their dues.

The centre is three years old and, according to a spokesman for ICGEB, member states have two more years to decide whether or not to contribute. "For the present, our centre is not doing badly," the spokesman said. Besides the annual contribution of $\$ 500,000$ from India and $\$ 1.2$ million from Italy, ICGEB has received a $\$ 400,000$ grant from the Rockefeller Foundation for research in rice biotechnology. These, plus the grant of nearly $\$ 2$ million from Wockhardt, have brightened the chances of ICGEB's survival. Nevertheless, even the most committed optimist would be hard pressed to predict that ICGEB will ever receive funding from most of the member states. 